. LA-UR- $9 \% 143$ ,

$$
\text { CONF-970111--5 }
$$

HIGH TEMPERATURE STRUCTURAL SILICIDES
Submitted to:

\section{Los Alamos}

NATIONAL LABORATORY

JOHN J. PETROVIC, MST-4

DISTRIBUTION OF THIS DOCUMENT IS IRMARTED

21st ANNUAI COCOA BEACH CONFERENCE AND EXPOSITION ON COMPOSITES, ADVANCED CERAMICS, MATERIALS AND STRUCTURES

JANUARY 12-16, 1997
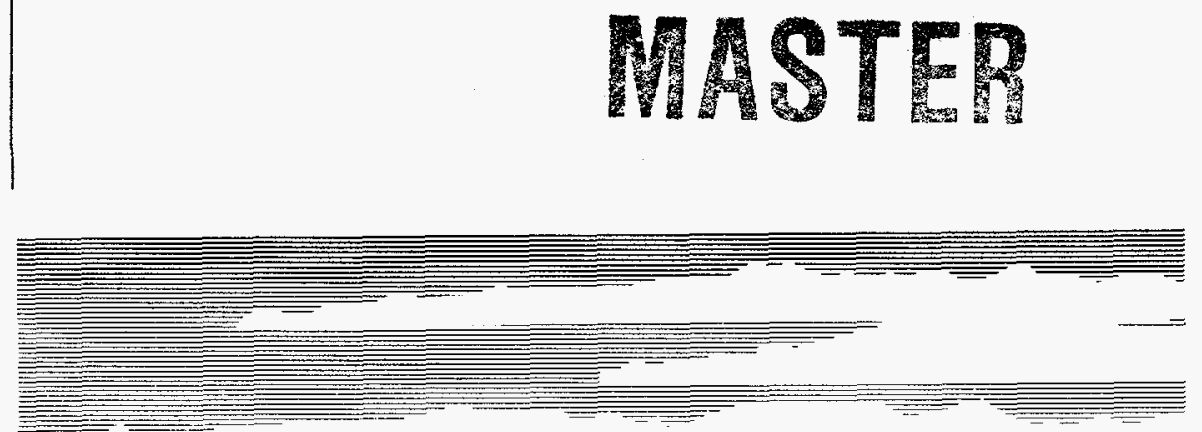

Los Alamos National Laboratory, an affirmative action/equal opportunity employer, is operated by the University of California tor the U.S. Department of Energy under contract W-7405-ENG-36. By acceptance of this . ?rticle, the publisher recognizes that the U.S. Government retains a nonexclusive, royalty-free license to publish or reproduce the published form of this contribution, or to allow others to do so, for U.S. Government purposes. The Los Alamos National Laboratory requests that the publisher identify this article as work performed under the auspices of the U.S. Department of Energy. 


\section{DISCLAIMER}

Portions of this document may be illegible in electronic image products. Images are produced from the best available original document. 


\section{DISCLAIMER}

This report was prepared as an account of work sponsored by an agency of the United States Government. Neither the United States Government nor any agency thereof, nor any of their employees, make any warranty, express or implied, or assumes any legal liability or responsibility for the accuracy, completeness, or usefulness of any information, apparatus, product, or process disclosed, or represents that its use would not infringe privately owned rights. Reference herein to any specific commercial product, process, or service by trade name, trademark, manufacturer, or otherwise does not necessarily constitute or imply its endorsement, recommendation, or favoring by the United States Government or any agency thereof. The views and opinions of authors expressed herein do not necessarily state or reflect those of the United States Government or any agency thereof. 


\title{
High Temperature Structural Silicides
}

\author{
John J. Petrovic \\ Laboratory Fellow \\ Ceramic Science and Technology Group MST-4 \\ Materials Science and Technology Division \\ Los Alamos National Laboratory \\ Los Alamos, New Mexico 87545
}

\begin{abstract}
:
Structural silicides have important high temperature applications in oxidizing and aggressive environments. Most prominent are $\mathrm{MoSi}_{2}$-based materials, which are borderline ceramic-intermetallic compounds. $\mathrm{MoSi}_{2}$ single crystals exhibit macroscopic compressive ductility at temperatures below room temperature in some orientations. Polycrystalline $\mathrm{MoSi}_{2}$ possesses elevated temperature creep behavior which is highly sensitive to grain size. $\mathrm{MoSi}_{2}-\mathrm{Si}_{3} \mathrm{~N}_{4}$ composites show an important combination of oxidation resistance, creep resistance, and low temperature fracture toughness. Current potential applications of $\mathrm{MoSi}_{2}$-based materials include furnace heating elements, molten metal lances, industrial gas burners, aerospace turbine engine components, diesel engine glow plugs, and materials for glass processing.
\end{abstract}

\section{Introduction:}

Over the past few years, structural silicides have emerged as important elevated temperature structural materials for applications in oxidizing and aggressive environments (1-3). There are a relatively large number of silicides know, most of which have seen little characterization of their properties (4). For structural purposes, the silicides of most interest are the transition metal silicides, and more particularly molybdenum-based silicides. 
In terms of structural materials that can be used in oxidizing environments, there is a temperature cutoff point at approximately $1000{ }^{\circ} \mathrm{C}$. Below this temperature materials such as nickel and cobalt-based superalloys can be employed, as well as materials such as titanium and nickel aluminides and $\mathrm{SiC}$ fiber reinforced glass-ceramics. However, above $1000{ }^{\circ} \mathrm{C}$, for oxidationresistance and elevated temperature strength reasons, one must resort to materials such as the silicon-based structural ceramics $\mathrm{Si}_{3} \mathrm{~N}_{4}$ and $\mathrm{SiC}$, advanced high temperature intermetallics such as $\mathrm{NiAl}$ and $\mathrm{NbCr}_{2}$, and the class of structural silicide materials, most notably $\mathrm{MoSi}_{2}$.

Potentially interesting and important structural silicides are shown in Table I. $\mathrm{MoSi}_{2}$ has been by far the most investigated due to its excellent oxidation resistance. $\mathrm{WSi}_{2}$ forms a complete solid solution with $\mathrm{MoSi}_{2}$. Mos $\mathrm{Mi}_{3}$ is adjacent to $\mathrm{MoSi}_{2}$ in the $\mathrm{Mo}-\mathrm{Si}$ phase diagram. $\mathrm{NbSi}_{2}$ and $\mathrm{TaSi}_{2}$ have exhibited single crystal ductility in some orientations at temperatures near room temperature. $\mathrm{Ti}_{5} \mathrm{Si}_{3}$ has a high melting point and low density.

Table I: Some Interesting Potential Structural Silicides

\begin{tabular}{|l|l|l|l|}
\hline Silicide & Melting Point $\left({ }^{\circ} \mathrm{C}\right)$ & Crystal Structure & Density $\left(\mathrm{g} / \mathrm{cm}^{3}\right)$ \\
\hline $\mathrm{MoSi}_{2}$ & 2030 & Tetragonal & 6.24 \\
\hline $\mathrm{WSi}_{2}$ & 2160 & Tetragonal & 9.86 \\
\hline $\mathrm{NbSi}_{2}$ & 1930 & Hexagonal & 5.66 \\
\hline $\mathrm{TaSi}_{2}$ & 2200 & Hexagonal & 9.10 \\
\hline $\mathrm{TiSi}_{2}$ & 1500 & Orthorohombic & 4.04 \\
\hline $\mathrm{CrSi}_{2}$ & 1490 & Hexagonal & 4.98 \\
\hline $\mathrm{CoSi}_{2}$ & 1326 & Cubic & 4.95 \\
\hline $\mathrm{YSi}_{2}$ & 1835 & Rhombohedral & 4.50 \\
\hline $\mathrm{Mo}_{5} \mathrm{Si}_{3}$ & 2160 & Tetragonal & 8.24 \\
\hline $\mathrm{Ti}_{5} \mathrm{Si}_{3}$ & 2130 & Hexagonal & 4.32 \\
\hline & \multicolumn{3}{|l}{} \\
\hline
\end{tabular}

\section{Characteristics of $\mathrm{MoSi}_{2}$ :}

As has been indicated, $\mathrm{MoSi}_{2}$ has received the most attention to date in the field of structural silicides. It is pertinent to ask the question: What is $\mathrm{MoSi}_{2}$ ? In order to answer this question, it is first necessary to address the question: What is a ceramic? Although there have been many definitions of a ceramic put forward, a definition which is both comprehensive and succinct is the following (1): A ceramic is a solid, iono-covalent, inorganic compound. Based on this definition of a ceramic, $\mathrm{MoSi}_{2}$ is then a borderline ceramic-intermetallic 
compound, since its atomic bonding is a combination of both covalent and metallic (5).

It is the collection of properties of $\mathrm{MoSi}_{2}$ that make it interesting as a high temperature structural material (1). $\mathrm{MoSi}_{2}$ has a high melting point of 2030 ${ }^{\circ} \mathrm{C}$. It has superb high temperature oxidation resistance, essentially equivalent to that of $\mathrm{SiC}$ since it forms a thin coherent and adherent protective silica layer. In polycrystalline form, $\mathrm{MoSi}_{2}$ exhibits a brittle-to-ductile transition in compression in the vicinity of $1000^{\circ} \mathrm{C}$ or lower, although some orientations of single crystals actually show macroscopic ductility at much lower temperatures. The material is thermodynamically stable with a wide range of structural ceramics, including $\mathrm{Si}_{3} \mathrm{~N}_{4}, \mathrm{SiC}, \mathrm{Al}_{2} \mathrm{O}_{3}, \mathrm{ZrO}_{2}$, mullite, $\mathrm{TiB}_{2}$, and TiC. Thus, there is a significant potential for composite development. It can also be alloyed with other high melting point silicides such as $\mathrm{WSi}_{2}, \mathrm{NbSi}_{2}, \mathrm{Mo}_{5} \mathrm{Si}_{3}$, and $\mathrm{Ti}_{5} \mathrm{Si}_{3}$. Due to the metallic nature of its bonding, $\mathrm{MoSi}_{2}$ can be electro-discharge machined, thus making it easier to machine than most structural ceramics. Finally, $\mathrm{MoSi}_{2}$ is an abundant, relatively low cost material, which is also environmentally benign.

In terms of engineering properties, $\mathrm{MoSi}_{2}$ has a thermal expansion coefficient close to that of $\mathrm{Al}_{2} \mathrm{O}_{3}$. Its thermal conductivity is intermediate between that of $\mathrm{Si}_{3} \mathrm{~N}_{4}$ and $\mathrm{SiC}$. The elastic modulus of $\mathrm{MoSi}_{2}$ is close to the elastic modulus of $\mathrm{SiC}$. While the high temperature oxidation resistance of $\mathrm{MoSi}_{2}$ is similar to that of $\mathrm{SiC}$, maximum oxidation rates in $\mathrm{MoSi}_{2}$ actually occur at the intermediate temperature of $500^{\circ} \mathrm{C}$.

\section{Single Crystal $\mathrm{MoSi}_{2}$ :}

The crystal structure of $\mathrm{MoSi}_{2}$ is tetragonal. The compressive deformation of single crystal $\mathrm{MoSi}_{2}$ has been investigated as a function of temperature (6-8). Figure 1 shows the compressive yield stress of $\mathrm{MoSi}_{2}$ single crystals as a function of temperature. There are two key points to be made about the data in Figure 1. First, elevated temperature strength in the [001] orientation is very high, essentially similar to that of c-axis sapphire. This suggests the potential for crystallographic texture development to increase high temperature mechanical strength, such as polycrystalline fiber or wire development with a [001] texture. The second key observation is that macroscopic compressive ductility occurs in some crystallographic orientations at temperatures as low as $100{ }^{\circ} \mathrm{C}$. This presents the possibility of significantly lowering the ductile-tobrittle transition temperature of $\mathrm{MoSi}_{2}$ by suitable alloying. 


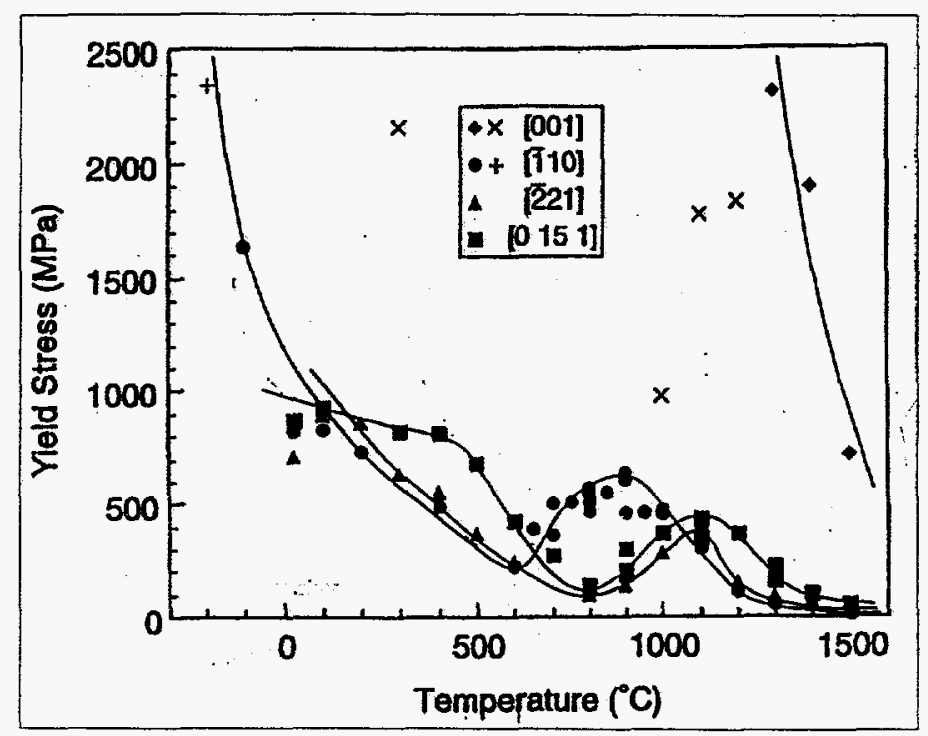

Figure 1: Compressive yield stress of $\mathrm{MoSi}_{2}$ single crystals as a function of temperature (8).

The observed slip systems in $\mathrm{MoSi}_{2}$ are $\{013\}<331>,\{110\}<111>$, $\{011\}<100\rangle,\{010\}<100\rangle$, and $\{023\}<100>(6-8)$. An anomalous behavior is observed for the $\{013\}<331>$ slip system, in that this slip system operates only at high temperatures for crystallographic orientations near [001], yet is observed to be operative at low temperatures for other crystallographic orientations (8). This unusual behavior is likely due to dislocation core effects. If the $\{013\}<331>$ slip system can be made to operate in the [001] orientation, then there is a significant possibility of markedly lowering the brittle-to-ductile transition of polycrystalline $\mathrm{MoSi}_{2}$ (8). The alloying of $\mathrm{MoSi}_{2}$ to promote this slip system is presently an active area of silicide research.

Figure 2 shows a room temperature Vickers indentation in single crystal $\mathrm{MoSi}_{2}$ oriented in the [001] direction (9). Both indentation cracks and dislocation slip lines are observed on the polished surface at room temperature. This indicates that $\mathrm{MoSi}_{2}$ is a semi-brittle material somewhat analogous to $\mathrm{MgO}$. The direction of the indentation cracks suggests that $\{100\}$ planes may be cleavage-type planes in $\mathrm{MoSi}_{2}$. If the slip trace planes are perpendicular to the plane of polish, then slip on $\{100\}$ and $\{110\}$ planes at room temperature is suggested. 

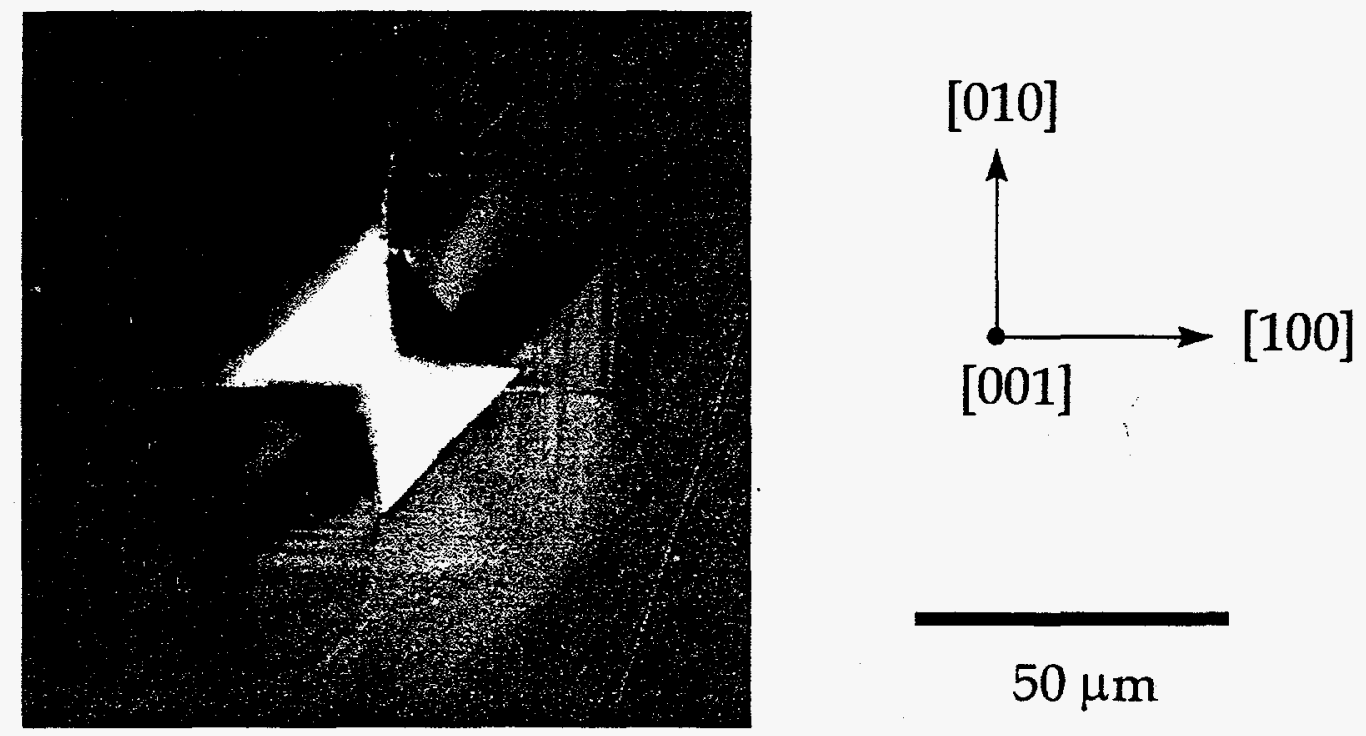

Figure 2: Room temperature 1000 gm Vickers indentation in single crystal $\mathrm{MoSi}_{2}$ (9).

\section{Polycrystalline $\mathrm{MoSi}_{2}$ :}

At the present time, polycrystalline $\mathrm{MoSi}_{2}$ is brittle at room temperature, with a polycrystalline fracture toughness of approximately $3 \mathrm{MPa} \mathrm{m} \mathrm{m}^{1 / 2}(10)$. It has been shown that at room temperature, the fracture mode of $\mathrm{MoSi}_{2}$ is $75 \%$ transgranular and 25\% intergranular (10). The brittle-to-ductile transition of large grained, low oxygen content $\mathrm{MoSi}_{2}$ has been investigated in both compression and bending (11). While a BDTT of approximately $1000^{\circ} \mathrm{C}$ is seen in compression, the BDTT in bending occurs at approximately $1350{ }^{\circ} \mathrm{C}$ in bending. The BDTT of polycrystalline $\mathrm{MoSi}_{2}$ is sensitive to both grain size and oxygen content, decreasing with decreasing grain size and increasing oxygen content. It has been shown that prestraining at $1300{ }^{\circ} \mathrm{C}$ can lower the BDTT of polycrystalline $\mathrm{MoSi}_{2}$ to appromately $750{ }^{\circ} \mathrm{C}$ (12). This is due to the introduction of mobile dislocations by the high temperature prestraining treatment.

The elevated temperature creep resistance of polycrystalline $\mathrm{MoSi}_{2}$ is highly sensitive to grain size (13). This effect is shown in Figure 3. The creep resistance of $\mathrm{MoSi}_{2}$ has been shown to increase by three orders of magnitude with only an $11 \mu \mathrm{m}$ increase in the grain size. A full explanation of this grain size sensitivity has not yet been obtained. However, the elevated temperature creep mechanisms in polycrystalline $\mathrm{MoSi}_{2}$ are known to be a combination of grain boundary sliding and dislocation plasticity (13). This grain size effect on creep 
resistance is important from the viewpoint of composite design for optimized creep properties.

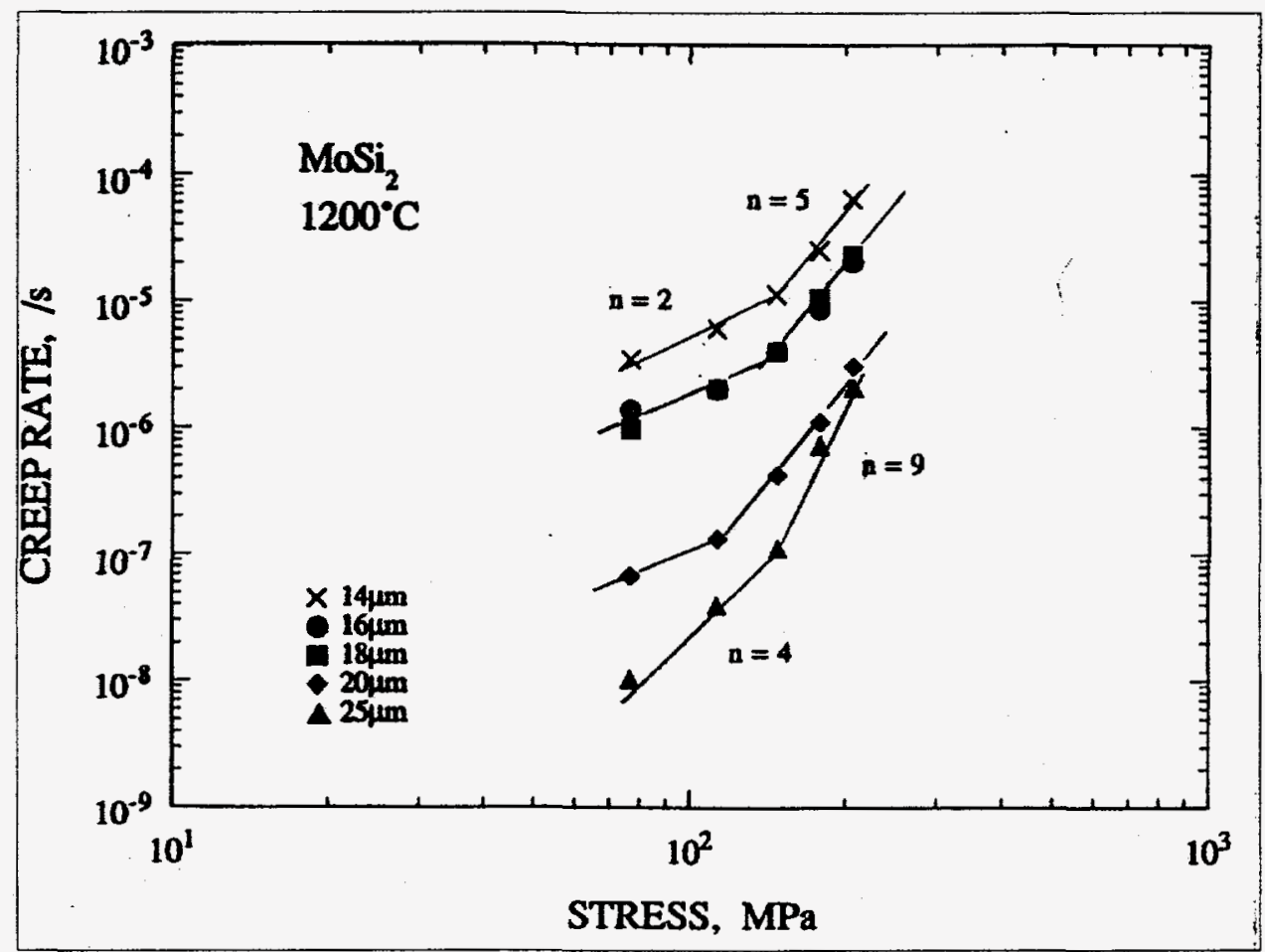

Figure 3: Effect of grain size on the creep of polycrystalline $\mathrm{MoSi}_{2}$ (13).

\section{$\mathrm{MoSi}_{2}$-based Composites:}

For $\mathrm{MoSi}_{2}$-based materials to be successfully employed in high temperature structural applications, both the high temperature creep resistance and the low temperature fracture toughness must be improved. The composite approach with ceramic reinforcements has been shown to yield such improvements, with no significant reduction in the oxidation resistance of these materials (1). Composites may be a $\mathrm{MoSi}_{2}$ matrix reinforced with ceramic, or a ceramic matrix reinforced with $\mathrm{MoSi}_{2}$.

Both $\mathrm{SiC}$ whisker and $\mathrm{SiC}$ particle reinforcements have been observed to significantly increase the elevated temperature creep resistance of $\mathrm{MoSi}_{2}$-based materials, and moderately increase the room temperature fracture toughness (1416). The addition of $\mathrm{ZrO}_{2}$ particles to a $\mathrm{MoSi}_{2}$ matrix can produce significant transformation toughening effects in $\mathrm{MoSi}_{2}$ composites, with the maximum toughening observed for unstabilized $\mathrm{ZrO}_{2}$ particles (17). 


\section{$\mathrm{MoSi}_{2}-\mathrm{Si}_{3} \mathrm{~N}_{4}$ Composites:}

The $\mathrm{MoSi}_{2}-\mathrm{Si}_{3} \mathrm{~N}_{4}$ composite system is a very interesting and important one. $\mathrm{MoSi}_{2}$ and $\mathrm{Si}_{3} \mathrm{~N}_{4}$ are thermodynamically stable compounds (18). Additions of $\mathrm{Si}_{3} \mathrm{~N}_{4}$ to a $\mathrm{MoSi}_{2}$ matrix significantly improve the intermediate temperature oxidation resistance of $\mathrm{MoSi}_{2}$ and its elevated temperature mechanical properties (19). Additions of $\mathrm{MoSi}_{2}$ to a $\mathrm{Si}_{3} \mathrm{~N}_{4}$ matrix allow for the electro-discharge machining of $\mathrm{Si}_{3} \mathrm{~N}_{4}$, and also lead to improved fracture toughness and elevated temperature oxidation characteristics $(20,21,22)$. Figure 4 shows the effects on room temperature fracture toughness and elevated temperature creep resistance of additions of $\mathrm{MoSi}_{2}$ to a $\mathrm{Si}_{3} \mathrm{~N}_{4}$ matrix (21).

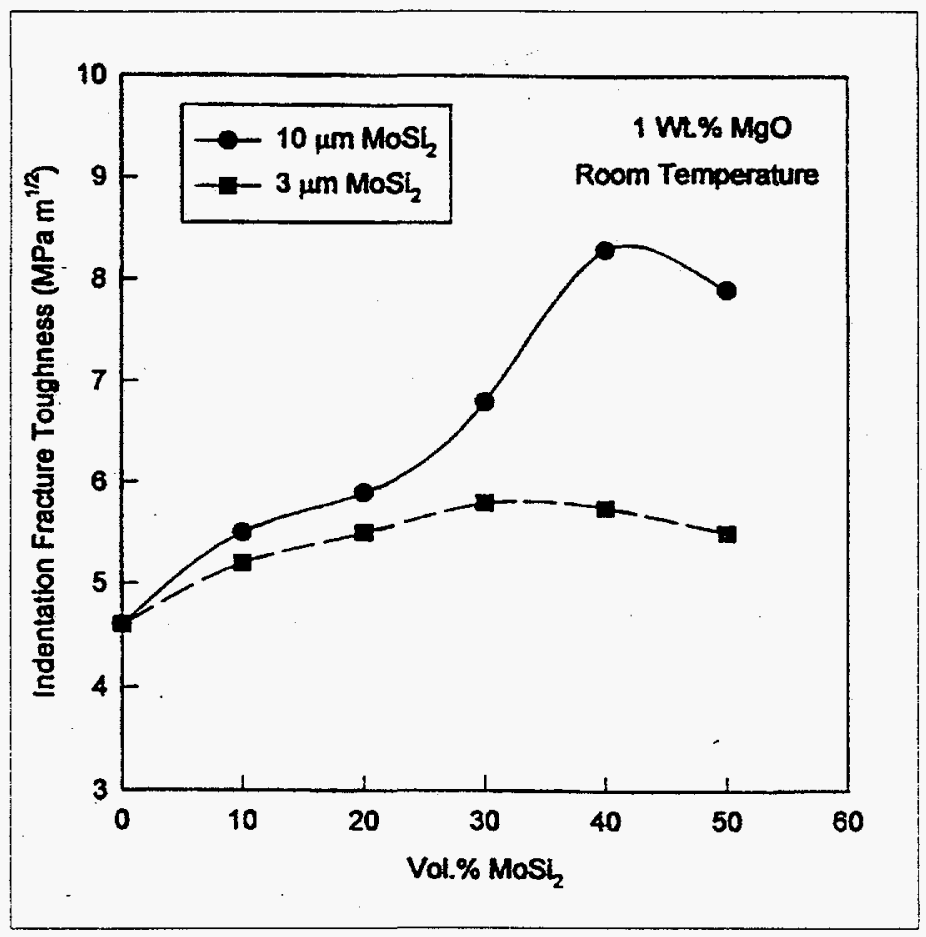




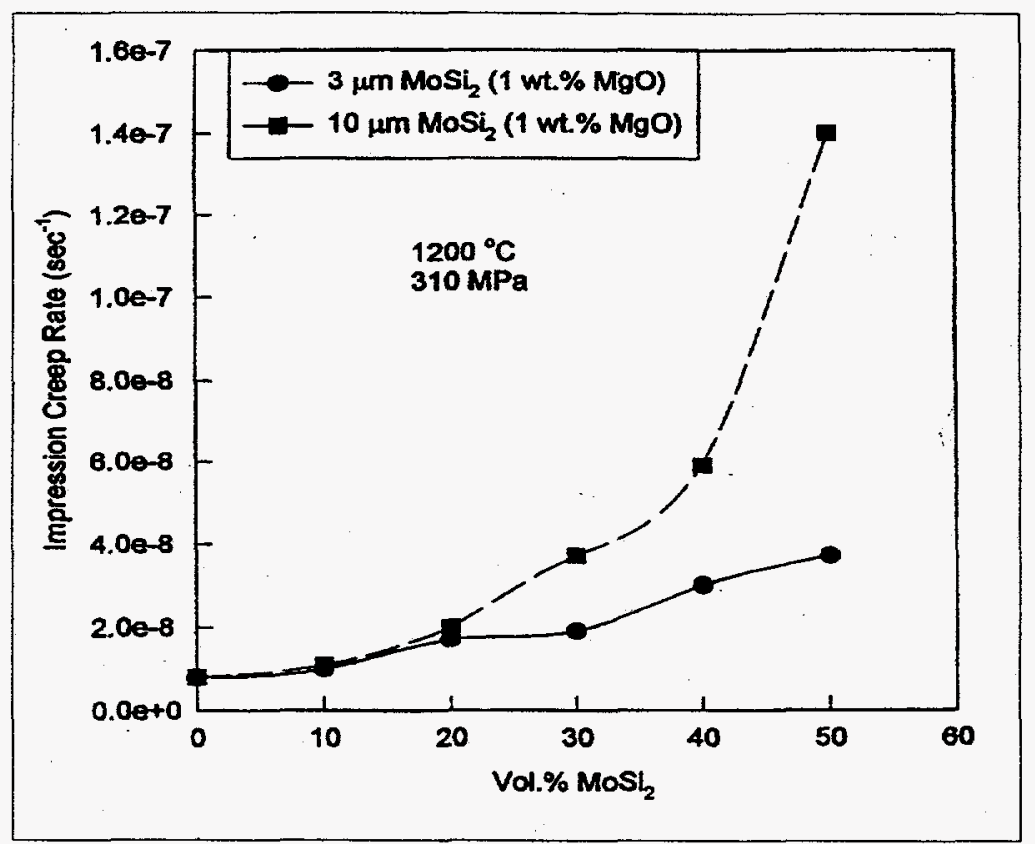

Figure 4: Room temperature fracture toughness and elevated temperature creep resistance of $\mathrm{MoSi}_{2}$ particle-Si${ }_{3} \mathrm{~N}_{4}$ matrix composites (21).

\section{Boron-Mos $\mathrm{Si}_{3}$ :}

The silicide compound $\mathrm{Mo}_{5} \mathrm{Si}_{3}$ is adjacent to $\mathrm{MoSi}_{2}$ in the Mo-Si phase diagram, and has a high melting point of $2160{ }^{\circ} \mathrm{C}$. A major drawback to its application has been the fact that its oxidation resistance is greatly inferior to that of $\mathrm{MoSi}_{2}$ (2). Recently, it has been shown that small additions of boron to $\mathrm{Mo}_{5} \mathrm{Si}_{3}$ significantly improve the oxidation resistance of this material (23). These small additions of boron lead to the formation of a protective borosilicate glass oxidation layer. Additionally, the boron additions produce the formation of a multiphase composite material consisting of $\mathrm{Mo}_{5} \mathrm{Si}_{3} \mathrm{~B}_{\mathrm{x}}, \mathrm{Mo}_{5}(\mathrm{SiB})_{3}, \mathrm{Mo}_{3} \mathrm{Si}$, $\mathrm{MoSi}_{2}$, and $\mathrm{MoB}$, with the exact phase composition depending on the level of boron addition. The boron- $\mathrm{Mo}_{5} \mathrm{Si}_{3}$ materials have been reported to possess good elevated temperature creep resistance (24).

\section{Applications of $\mathrm{MoSi}_{2}$-based Materials:}

$\mathrm{MoSi}_{2}$-based materials are beginning to develop a broad base of important industrial applications. These applications are driven by the elevated temperature 
mechanical properties of these materials, in combination with other properties such as electrical conductivity and oxidation/corrosion resistance.

\section{Heating Elements:}

$\mathrm{MoSi}_{2}$ materials have been employed for a number of years as heating elements for air furnaces. The recent Kanthal Super 1900 heating elements can operate at an element temperature of $1900^{\circ} \mathrm{C}$ in air and oxidizing environments. These Super 1900 elements are actually a solid solution alloy of $\mathrm{MoSi}_{2}$ and $\mathrm{WSi}_{2}$. The major problems with the $\mathrm{MoSi}_{2}$-based heating elements are brittle fracture, which makes the elements difficult to handle, and high temperature creep, which causes the elements to deform. Both of these aspects limit element life, as well as affect furnace design. Current elements are U-shaped and typically hung vertically due to limitations in mechanical properties. As both the fracture toughness and creep resistance of $\mathrm{MoSi}_{2}$-based materials continue to improve by composite and alloying approaches, there will be significant effects on enhanced furnace element lifetime as well as greater flexibility in furnace design.

\section{Molten Metal Lances:}

A number of foundry operations require that gases be injected into molten metals. Microlaminate $\mathrm{MoSi}_{2}-\mathrm{Al}_{2} \mathrm{O}_{3}$ composite tubes were fabricated by plasma spray forming (25). These tubes were then tested as inert gas lances in molten aluminum alloy at $725^{\circ} \mathrm{C}$ and molten copper at $1200{ }^{\circ} \mathrm{C}$. The $\mathrm{MoSi}_{2}-\mathrm{Al}_{2} \mathrm{O}_{3}$ composites performed very well in both molten metals (25). In the case of the molten copper, alternative tube materials of graphite and $\mathrm{SiC}$ were also tested for comparison. The graphite tube lasted for only fifteen minutes in the molten copper, while the $\mathrm{SiC}$ tube thermal shocked upon immersion in the molten copper. In contrast, the $\mathrm{MoSi}_{2}-\mathrm{Al}_{2} \mathrm{O}_{3}$ microlaminate tube withstood four hours in the molten copper and could have lasted longer, however the test was terminated at the four hour mark The composite tube was resistant to chemical attack by the molten copper due to the presence of the $\mathrm{Al}_{2} \mathrm{O}_{3}$ phase, while it exhibited thermal shock resistance and "graceful failure" type mechanical behavior due to plastic deformation of the $\mathrm{MoSi}_{2}$ phase (25).

\section{Industrial Gas Burners:}

The industrial gas burner industry is in the process of developing gas burners which will burn oxygen-natural gas mixtures rather than air-natural gas mixtures, in order to reduce $\mathrm{NO}_{\mathrm{x}}$ environmental emissions. Because such 
oxygen-natural gas burners must operate at higher temperatures than air-natural gas burners, there is a need to develop new burner materials which are resistant to the oxygen-natural gas combustion environment. Studies have shown that $\mathrm{MoSi}_{2}$ possesses significant resistance to oxygen-natural gas combustion at high temperatures (26). After an initial transient period, material stability is achieved through the formation of a stable $\mathrm{Mo}_{5} \mathrm{Si}_{3}$ layer. Stability occurs under both stoichiometric and fuel-rich combustion conditions. Prototype $\mathrm{MoSi}_{2}$ gas burners have been fabricated by a plasma spray forming process (27).

\section{Aerospace Gas Turbine Engines:}

Pratt \& Whitney has been developing advanced materials for a blade outer air seal (BOAS) hot section component of its gas turbine engines. In the engine, the BOAS is a stationary part which is located directly opposite of the rotating hot section turbine blades. The purpose of the BOAS is to maintain a small gap of stable dimensions between itself and the turbine blade. If this gap widens during operation of the turbine, it directly affects the turbine efficiency. Although stationary, the BOAS is exposed to high turbine gas temperatures and significant thermal stresses.

Gas burner testing by Pratt \& Whitney has shown that $\mathrm{MoSi}_{2}-\mathrm{SiC}$ and $\mathrm{MoSi}_{2}-\mathrm{Si}_{3} \mathrm{~N}_{4}$ composites possess significant thermal shock resistance in the simulated jet fuel combustion environment (28). These materials survived 250 cycles from room temperature to $1500{ }^{\circ} \mathrm{C}$ with no failures. Recent work at NASA-Lewis has concentrated on $\mathrm{MoSi}_{2}-\mathrm{Si}_{3} \mathrm{~N}_{4}$ composites reinforced with $\mathrm{SiC}$ continuous fibers. Thermomechanical Charpy impact tests as a function of temperature (which are designed to evaluate the material resistance to foreign impact damage in the engine) have demonstrated that these composite materials absorb significant impact energy at both room temperature and elevated temperatures (29).

\section{Diesel Engines:}

$\mathrm{MoSi}_{2}-\mathrm{Si}_{3} \mathrm{~N}_{4}$ composite diesel engine glow plugs have recently been developed by Toyota Central R\&D in Japan (30). The $\mathrm{MoSi}_{2}-\mathrm{Si}_{3} \mathrm{~N}_{4}$ glow plugs contain $30-40$ vol. \% $\mathrm{MoSi}_{2}$ phase in a $\mathrm{Si}_{3} \mathrm{~N}_{4}$ matrix. These glow plugs have two distinct practical advantages over metal glow plugs. First, they are highly resistant to the diesel fuel combustion environment and thus have a long lifetime of approximately thirteen years. Second, they can be heated at higher heating rates with the result that the diesel engine can be started faster. An inner composite cylinder with an interconnected $\mathrm{MoSi}_{2}$ phase provides the necessary 
electrical conductivity for the glow plug application. An outer, non-conducting sheath of the same $\mathrm{MoSi}_{2}-\mathrm{Si}_{3} \mathrm{~N}_{4}$ phase composition is employed as a cover for the inner conducting composite and has the same thermal expansion coefficient and thermal conductivity. This microstructural tailoring of the $\mathrm{MoSi}_{2}-\mathrm{Si}_{3} \mathrm{~N}_{4}$ composite allows for optimum performance of the diesel glow plug.

\section{Glass Processing:}

At the present time, metals and ceramic refractories are primarily employed in applications and components requiring contact with molten glasses. The refractory metal molybdenum is highly resistant to corrosion when immersed in molten glass. However, due to its poor oxidation resistance, it cannot be employed at or above the molten glass line. The precious metal platinum is also employed in contact with molten glasses, but this material is very expensive. The AZS multiphase refractory ceramic (Alumina-Zirconia-Silica) is also used for containing molten glasses, but suffers from relatively poor mechanical properties.

Recently, it has been shown that $\mathrm{MoSi}_{2}$ is also a material which is quite resistant to corrosion by molten glasses (31-33). $\mathrm{MoSi}_{2}$ shows excellent corrosion resistance below the glass line due to $\mathrm{Mo}_{5} \mathrm{Si}_{3}$ formation, and excellent oxidation resistance above the glass line due to $\mathrm{SiO}_{2}$ formation. While corrosion rates of $\mathrm{MoSi}_{2}$ are somewhat higher at the glass line than below the glass line, it has been reported that anodic protection of the $\mathrm{MoSi}_{2}$ significantly lowers corrosion rates at the glass line (33).

This corrosion resistance of $\mathrm{MoSi}_{2}$ to moiten glasses in combination with its elevated temperature mechanical properties has recently lead to the Kanthal Corporation marketing a new $\mathrm{MoSi}_{2}$ immersion tube for the injection of gases into molten glass (34). It has also initiated a Cooperative Research and Development Agreement (CRADA) between the Los Alamos National Laboratory and Schuller International Inc. (35). Schuller International is a major U.S. producer of fiberglass, and the objective of the CRADA is the development of $\mathrm{MoSi}_{2}$-based materials for fiberglass processing applications and components.

\section{Acknowledgements:}

The author would like to acknowledge the DOE-Office of Industrial Technologies/Advanced Industrial Materials (DOE/OIT-AIM), the Office of Naval Research (ONR), and the DOE-Office of Basic Energy Sciences/Division of Materials Science (DOE/OBES-DMS) for supporting various aspects of the high temperature structural silicide research at the Los Alamos National Laboratory described in this paper. He would also like to acknowledge the many 
other people at Los Alamos who have contributed to the structural silicide research activities there.

\section{References:}

1. J.J. Petrovic, "MoSi ${ }_{2}$-Based High-Temperature Structural Silicides", MRS Bulletin, XVI, (7), 35-40 (1993).

2. A.K. Vasudevan and J.J. Petrovic, "A Comparative Overview of Molybdenum Disilicide Composites", Mat. Sci. Eng., A155, 1-17 (1992).

3. J.J. Petrovic and A.K. Vasudevan, "Overview of High Temperature Structural Silicides", Mat. Res. Soc. Symp. Proc., 322, 3-8 (1994).

4. A. Aronsson, T. Lundstrom, and S. Rundqist, "Borides, Silicides and Phosphides", Methuen, London, c. 1965, p. 17.

5. M. Alouani, R.C. Albers, and M. Methfessel, "Calculated Elastic Constants and Structural Properties of Mo and $\mathrm{MoSi}_{2}$," Phys. Rev. B, 43 , 6500-6509 (1991).

6. Y. Umakoshi, T. Sakagami, T. Hirano, and T. Yamane, "High Temperature Deformation of $\mathrm{MoSi}_{2}$ Single Crystals with the C11 $\mathrm{b}_{\mathrm{b}}$ Structure", Acta Metall. Mater., 38, 909-915 (1990).

7. S.A. Maloy, T.E. Mitchell, J.J. Petrovic, A.H. Heuer, and J.J. Lewandowski, "The Temperature and Strain Rate Dependence of the Flow Stress in $\mathrm{MoSi}_{2}$ Single Crystals", Mater. Res. Soc. Symp. Proc., 322, 21 (1994).

8. K. Ito, H. Inui, Y. Shirai, and M. Yamaguchi, "Plastic Deformation of $\mathrm{MoSi}_{2}$ Single Crystals", Phil. Mag. A, 72, 1075-1097 (1995).

9. J.J. Petrovic and R.K. Wade, unpublished research.

10. R.K. Wade and J.J. Petrovic, "Fracture Modes in $\mathrm{MoSi}_{2}$ ", J. Am. Ceram. Soc., 75, 1682-1684 (1992).

11. R.M. Aikin, Jr., "On the Ductile-to-Brittle Transition Temperature in MoSi 2 ", Scripta Metall., 26, 1025 (1992). 
12. R. Gibala, H. Chang, and C.M. Czarnik, "Plasticity Enhancement Processes in $\mathrm{MoSi}_{2}$-Base Materials", Mater. Res. Soc. Symp. Proc., 322, 175 (1994).

13. K. Sadananda, C.R. Feng, H.N. Jones, and J.J. Petrovic, "Creep of Intermetallic Composites", in Proc. Int. Symp. On Structural Intermetallics, Seven Springs, 26-30 September 1993.

14. J.J. Petrovic and R.E. Honnell, "SiC Reinforced-MoSi $2 / \mathrm{WSi}_{2}$ Alloy Matrix Composites", Ceram. Eng. Sci. Proc., 11, 734-744 (1990).

15. A.K. Bhattacharya and J.J. Petrovic, "Hardness and Fracture Toughness of SiC-Particle-Reinforced $\mathrm{MoSi}_{2}$ Composites", J. Am. Ceram. Soc., 74, 27002703 (1991).

16. K. Sadananda and C.R. Feng, "A Review of Creep of Silicides and Composites", Mat. Res. Soc. Symp. Proc., 322, 157-173 (1994).

17. J.J. Petrovic, R.E. Honnell, T.E. Mitchell, R.K. Wade, and K.J. McClellan, " $\mathrm{ZrO}_{2}$-Reinforced $\mathrm{MoSi}_{2}$ Matrix Composites", Ceram. Eng. Sci. Proc., $\underline{12}$, 1633-1642 (1991).

18. E. Heikinheimo, A. Kodentsov, J.A. Van Beek, J.T. Klomp, and F.J.J. Van

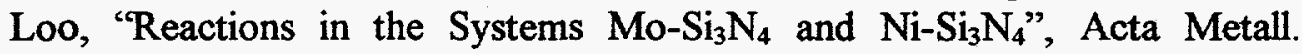
Mater., 40, S111-S119 (1992).

19. M.G. Hebsur, "Pest Resistant and Low CTE $\mathrm{MoSi}_{2}$-Matrix for High Temperature Structural Applications", Mat. Res. Soc. Symp. Proc., $\underline{350}$, 177-182 (1994).

20. J.J. Petrovic, M.I. Pena, and H.H. Kung, "Fabrication and Microstructures of $\mathrm{MoSi}_{2}$ Reinforced-Si $\mathrm{N}_{4}$ Matrix Composites", accepted for publication in the Journal of the American Ceramic Society, 1996.

21. J.J. Petrovic, M.I. Pena, I.E. Reimanis, M.S. Sandlin, S. Conzone, H.H. Kung, and D.P. Butt, "Mechanical Behavior of $\mathrm{MoSi}_{2}$ Reinforced- $\mathrm{Si}_{3} \mathrm{~N}_{4}$ Matrix Composites", submitted for publication in the Journal of the American Ceramic Society, 1997. 
22. H. Klemm, K. Tangermann, C. Schubert, and W. Hermel, "Influence of Molybdenum Silicide Additions on High-Temperature Oxidation Resistance of Silicon Nitride Materials", J. Am. Ceram. Soc., 79, 2429-2435 (1996).

23. M.K. Meyer and M. Akinc, "Oxidation Behavior of Boron-Modified $\mathrm{Mo}_{5} \mathrm{Si}_{3}$ at $800^{\circ} \mathrm{C}-1300{ }^{\circ} \mathrm{C} "$, J. Am. Ceram. Soc., $\underline{79}$, 938-944 (1996).

24. M.K. Meyer, M.J. Kramer, and M. Akinc, "Compressive Creep Behavior of $\mathrm{Mo}_{5} \mathrm{Si}_{3}$ with the Addition of Boron", Intermetallics, 4, 273-281 (1996).

25. A.H. Bartlett, R.G. Castro, D.P. Butt, H. Kung, and J.J. Petrovic, "Plasma Sprayed $\mathrm{MoSi}_{2} / \mathrm{Al}_{2} \mathrm{O}_{3}$ Laminate Composite Tubes as Lances in Pyrometallurgical Operations", Industrial Heating, January 1996 Issue.

26. W-Y Lin and R.F. Speyer, "Surface Oxidation Mechanisms of Molybdenum Disilicide in High-Temperature Combustion Environments", Mat. Res. Soc. Symp. Proc., 322, 267-272 (1994).

27. R.G. Castro, J.R. Hellmann, A.E. Segall, and D.L. Shelleman, "Fabrication and Testing of Plasma-Spray Formed $\mathrm{MoSi}_{2}$ and $\mathrm{MoSi}_{2}$ Composite Tubes", Mat. Res. Soc. Symp. Proc., 322, 81-86 (1994).

28. R. Hecht, Pratt \& Whitney, private communication.

29. M.G. Hebsur and M.V. Nathal, NASA-Lewis Research Center, private communication.

30. K. Yamada, Toyota Central Research \& Development, private communication.

31. S.K. Sundaram, J-Y Hsu, and R.F. Speyer, "Molten Glass Corrosion Resistance of Immersed Combustion-Heating Tube Materials in Soda-LimeSilicate Glass", J. Am. Ceram. Soc., 77, 1613-1623 (1994).

32. S.K. Sundaram, J-Y Hsu, and R.F. Speyer, "Molten Glass Corrosion Resistance of Immersed Combustion-Heating Tube Materials in E-Glass", J. Am. Ceram. Soc., 78, 1940-1946 (1995). 
33. S.K. Sundaram and R.F. Speyer, "Electrochemical Corrosion and Protection of Molybdenum and Molybdenum Disilicide in a Molten Soda-Lime-Silicate Glass Environment", J. Am. Ceram. Soc., 79, 1851-1856 (1996).

34. "Kanthal Super Bubbling Tubes in Glass Melting Tanks", The Kanthal Corporation, Furnace Products, 1995.

35. CRADA No. LA95C10271-A001 between the Los Alamos National Laboratory and Schuller International Inc., 19 March 1996. 